\title{
EDITORIAL
}

\section{Telehealth in practice: using Normalisation Process Theory to bridge the translational gap}

See linked article by Godden and King on pg 415

\section{Deborah Morrison ${ }^{a}$} *Frances S Mair ${ }^{b}$

a Academic Fellow, General Practice and Primary Care, Institute of Health and WellBeing, University of Glasgow, Glasgow, UK

b Professor of Primary Care Research, General Practice and Primary Care, Institute of Health and WellBeing, University of Glasgow, Glasgow, UK

\section{*Correspondence:}

Professor Frances Mair

Professor of Primary Care Research General Practice and Primary Care Institute of Health and WellBeing University of Glasgow

1 Horselethill Road

Glasgow

G12 9LX

UK

Tel: +44 (0)1413308317

Fax: +44 (0)1413308331

E-mail: frances.mair@glasgow.ac.uk

Commissioned article

Not externally peer-reviewed

Accepted 1st October 2011

Online 24th October 2011
Telehealth is increasingly seen as one strategy for counteracting the challenges of providing health care to populations who are now living longer with chronic diseases and for improving access for those living in geographically disperse locations. ${ }^{1}$ Despite the obvious potential of telehealth and a plethora of pilot and demonstration projects of varying size, there still remain relatively few well established services in routine practice. $^{2}$ A key problem has been that of integrating telehealth into professionals' patterns of work. In this issue of the PCRJ, Godden and King ${ }^{3}$ acknowledge that the potential of telehealth can be limited by a failure of the intervention to integrate into standard clinical practice. Consequently they sought to establish the distribution of potential patients and the willingness of care providers to adopt telehealth interventions as a prerequisite to considering the implementation of such an intervention.

The importance of such an approach has been emphasised in the updated MRC guidelines on developing and evaluating complex interventions. ${ }^{4}$ The use of theory when considering implementability is recommended to enhance the transfer of research findings into clinical practice. ${ }^{5}$ One such theory is Normalisation Process Theory (NPT), described as being "concerned with the social organisation of the work (implementation) of making practices routine elements of everyday life (embedding) and of sustaining embedded practices in their social contexts (integration)" - which was developed in response to the evidence that this implementation, embedding and integration rarely happens in practice..$^{6,7}$

NPT grew originally from the Normalisation Process Model (NPM), ${ }^{8}$ utilised by Godden and King in their paper. ${ }^{3}$ NPM proposes that complex interventions are implemented through processes where the collective action and interactions of patients, professionals and others are governed by four constructs: interactional workability (the ways in which telehealth helps or hinders professionals in performing various aspects of their work); relational integration (professionals' confidence in the safety or security of telehealth); skill set workability (how workload and training requirements are affected); and contextual integration (issues of resource allocation, infrastructure and policy). ${ }^{9}$ Focussing on these constructs and utilising NPM is appropriate when examining how telehealth is put into operation in practice. ${ }^{10}$

NPM does not, however, explain how interventions are formed in ways that are sustained, how actors are enrolled into them, or how new interventions are appraised. May and Finch collaborated to extend the model to a middle range theory (NPT) ${ }^{6}$ by exploring new domains of coherence (the work of making a complex intervention hold together and cohere to its context), cognitive participation (the work of engaging and legitimising a complex intervention) and reflexive monitoring (the work of understanding and evaluating a complex intervention in practice). Within this extended model, 'collective action' represents NPM and is just one of four constructs or types of 'work' which can be characterised when considering the evaluation and implementation of interventions. ${ }^{6,7,11}$

These constructs are applicable regardless of whether its use is at the stage of developing a complex intervention, optimising trial parameters, or the actual implementation of complex interventions. ${ }^{12}$ Therefore, NPT provides a straightforward conceptual framework - whose accessibility has been improved through translation into a web-based toolkit ${ }^{13}$ - to help clinicians, researchers and managers describe and (importantly) to judge the implementation potential of an intervention, either allowing for improvement and development prior to 
implementation, or if required an acceptance that the intervention simply lacks implementability and that further work is not warranted. ${ }^{12}$ In this latter role, NPT can be seen as a potential "Trial Killer"; it might be used to determine whether trials of complex interventions should proceed or not, depending on whether it seems likely they could become part of routine practice. ${ }^{12}$ There are further examples of its use in other disease areas, telehealth, ${ }^{14,15}$ and also in novel applications such as characterising the 'work' that patients themselves have to do when managing chronic illnesses such as heart failure. ${ }^{16}$

Using NPM to assess implementability, as Godden \& King have done, is valuable. It identifies potential problems for professionals wanting to incorporate telehealth into their everyday work. NPM, and particularly NPT, may help us bridge the translational gap by identifying possible barriers to the implementation of new services, thereby allowing implementers to focus efforts on addressing areas likely to be particularly problematic. But it should be noted that NPT is about "workability in practice" - and the way people perceive whether something might or might not work in practice can change when services are being used regularly. ${ }^{17,18}$ Views on interactional workability and relational integration issues can change with use; for example, users might lose confidence in a system and score it poorly for relational integration if there are persistent technical or reliability problems. ${ }^{19}$ Therefore, implementers should use NPT in an iterative way when implementing services, with preliminary work - as described by Godden \& King ${ }^{3}$ - serving to sensitise implementers to potential problems. However, they need to be aware of difficulties in other areas that might arise following the real-life use of systems.

\section{Conflicts of interest}

Professor Mair has contributed through funded grants from the ESRC/SDO NIHR and elsewhere to the development and dissemination of Normalization Process Theory, including the Normalization Process Theory Toolkit mentioned in this editorial. Dr Morrison has no conflicts of interest.

\section{References}

1. McLean S, Protti D, Sheikh A. Telehealthcare for long term conditions. BMJ 2011;342:374-8.

2. House of Commons Health Committee. The Use of New Medical Technologies within the NHS, volume 2: Oral and Written Evidence. 2005. London, The Stationary Office Limited.

3. Godden DJ, King G. Rational development of telehealth to support primary care respiratory medicine: patient distribution and organisational factors. Prim Care Respir J 2011;20(4):415-20. http://dx.doi.org/10.4104/pcrj.2011.00063

4. Medical Research Council. Developing and evaluating complex interventions: new guidance. 2008. London, MRC.
5. Eccles MP, Armstrong D, Baker R, et al. An implementation research agenda. Implementation Science 2009;4:18.

6. May C, Finch T. Implementing, Embedding, and Integrating Practices: An Outline of Normalization Process Theory. Sociology 2009;43(3):535-54. http://dx.doi.org/10.1177/0038038509103208

7. May CR, Mair F, Finch T, et al. Development of a theory of implementation and integration: Normalization Process Theory. Implement Sci 2009;4:29. http://dx.doi.org/10.1186/1748-5908-4-29

8. May C, Finch T, Mair F, et al. Understanding the implementation of complex interventions in health care: the normalization process model. BMC Health Services Research 2007;7:148. http://dx.doi.org/10.1186/1472-6963-7-148

9. May CR, Mair FS, Dowrick CF, Finch TL. Process evaluation for complex interventions in primary care: understanding trials using the normalization process model. BMC Family Practice 2007;8:42. http://dx.doi.org/ 10.1186/1471-2296-8-42

10. Elwyn G, Legare F, van der Weijden T, Edwards A, May C. Arduous implementation: does the Normalisation Process Model explain why it's so difficult to embed decision support technologies for patients in routine clinical practice. Implement Sci 2008;3:57. http://dx. doi.org/10.1186/1748-5908-3-57

11. Mair F, May C, Murray E, et al. Understanding the implementation and integration of e-Health Services. Report for the NHS Service and Delivery R and D Organisation (NCCSDO). 2009. London, SDO.

12. Murray E, Treweek S, Pope C, et al. Normalisation process theory: a framework for developing, evaluating and implementing complex interventions. BMC Medicine 2010;8:63. http://dx.doi.org/10.1186/1741-7015-8-63

13. May C, Murray E, Finch T, et al. Normalization Process Theory On-line Users' Manual and Toolkit. Available from http://www.normalizationprocess.org. 2010. Accessed 22nd September 2011.

14. May C, Finch T, Cornford J, et al. Integrating telecare for chronic disease management in the community: What needs to be done? BMC Health Services Research 2011;11(1):131. http://dx.doi.org/10.1186/1472-6963-11-131

15. Gunn J, Palmer V, Dowrick $C$, et al. Embedding effective depression care: using theory for primary care organisational and systems change. Implementation Science 2010;5(1):1-15. http://dx.doi.org/10.1186/1748-5908-5-62

16. Gallacher K, May CR, Montori VM, Mair FS. Understanding patients' experiences of treatment burden in chronic heart failure using normalization process theory. Ann Fam Med 2011;9(3):235-43. http://dx.doi.org/ 10.1370/afm.1249

17. Finch TL, Mair FS, May CR. Teledermatology in the UK: lessons in service innovation. $\mathrm{Br} J$ Dermatol 2007;156(3):521-7. http://dx.doi.org/10.1111/ j.1365-2133.2006.07608.x

18. May C, Gask L, Atkinson T, Ellis N, Mair F, Esmail A. Resisting and promoting new technologies in clinical practice: the case of telepsychiatry. Soc Sci Med 2001;52(12):1889-901. http://dx.doi.org/10.1016/S0277-9536(00)00305-1

19. Mair FS, Hiscock J, Beaton SC. Understanding factors that inhibit or promote the utilization of telecare in chronic lung disease. Chronic Illness 2008; 4(2):110-17. http://dx.doi.org/10.1177/1742395308092482

\section{Available online at http://www.thepcrj.org}

